\title{
Dampak Tumpang Tindih Keberadaan BRT Trans-Jateng (Mangkang - Weleri) terhadap Angkutan Umum Daerah di Kabupaten Kendal
}

\author{
Sri Rejeki Laku Utami ${ }^{1}$, Adib Wahyu Hidayat ${ }^{2}$, Ahmad Shochih $^{3}$, Yeni Selfia ${ }^{4}$ \\ ${ }^{1}$ Program Studi Teknik Sipil, Fakultas Teknik dan Rekayasa, Universitas Selamat Sri
}

Email: ${ }^{1}$ udhitami@gmail.com, 2 dibwah07@gmail.com

\begin{abstract}
Transportation is a transfer from one place to another with a mode of transportation both land, sea and air. Public transportation is a mode of public service transportation that has a function in providing transportation services in the form of passenger comfort, very affordable fares and a sense of security for public transportation passengers.. This study was conducted to determine the overlap of the existence of BRT Trans Jateng (Mangkang-Weleri) on Regional Public Transportation in Kendal Regency as a solution or alternative policy that can be done to overcome the impact of the overlap. In this study using quantitative methods with observation techniques in the field, interview methods, questionnaires and documentation. The result of this study is the analysis of data that has been conducted field observations as well as the dissemination of questionnaires on the situation of BRT Trans Jateng passengers (Makang -Weleri) as a descriptive analysis. The results of this research data analysis showed the impact of overlap in BRT Trans Jateng (Mangkang-Weleri) on Regional Public Transportation in Kendal by 54.2\%. Some alternative policies that can be done to reduce the impact of overlap such as scheduling the departure of public transportation BRT Trans Jateng (Mangkang-Weleri) can be conditioned with regional public transportation. In addition, there is a cooperation between the Provincial Government of Central Java and The Government of Kendal and the owner of AUD (Regional Public Transport) in Kendal Regency related to the departure schedule of the BRT Trans-Jateng (Mangkang-Weleri) bus fleet with Regional Public Transport.
\end{abstract}

Keywords: Overlapping, Trans Central Java BRT (Mangkang-Weleri), Regional Public Transport.

\begin{abstract}
Abstrak
Transportasi merupakan perpindahan dari suatu tempat ke tempat lain dengan moda transportasi baik darat, laut dan udara. Angkutan umum adalah moda transportasi pelayanan masyarakat yang memiliki fungsi dalam memberikan pelayanan transportasi yang berupa kenyamanan penumpang, harga tarif yang sangat terjangkau dan rasa aman yang dimiliki bagi penumpang transportasi umum. Penelitian ini dilakukan untuk mengetahui tumpang tindih keberadaan BRT Trans Jateng (Mangkang-Weleri) terhadap Angkutan Umum Daerah di Kabupaten Kendal sebagaimana solusi atau alternatif kebijakan yang bisa dilakukan untuk mengatasi dampak tumpang tindih. Penelitian ini menggunakan metode kuantitatif dengan teknik observasi dilapangan, metode wawancara, angket/kuesioner dan dokumentasi. Hasil dari penelitian ini adalah analisis data yang telah dilakukan observasi lapangan serta penyebaran angket mengenai situasi penumpang BRT Trans Jateng (Makang -Weleri) sebagai analisis secara deskritif. Hasil dari analisis data penelitian ini menunjukkan dampak tumpang tindih dalam BRT Trans Jateng (Mangkang-Weleri) terhadap Angkutan Umum Daerah di Kabupaten Kendal. Tumpang tindih keberadaan BRT Trans Jateng (Mangkang-Weleri) dengan bus angkutan umum daerah sebesar 54,2\%. Beberapa alternatif kebijakan yang dapat dilakukan untuk mengurangi dampak tumpang tindih seperti penjadwalan keberangkatan transportasi umum BRT Trans Jateng (Mangkang-Weleri) bisa dikondisikan dengan angkutan umum daerah. Selain itu, adanya kerjasama antara Pemprov Jateng dengan PemKab Kendal serta pemilik AUD (Angkutan Umum Daerah) di Kabupaten Kendal terkait dengan jadwal keberangkatan armada bus BRT Trans Jateng (Mangkang-Weleri) dengan Angkutan Umum Daerah.
\end{abstract}

Kata Kunci: Tumpang Tindih, BRT Trans Jateng (Mangkang-Weleri), Angkutan Umum Daerah. 


\section{Pendahuluan}

Jawa Tengah termasuk provinsi yang memiliki beberapa Kabupaten. Salah satunya Kabupaten Kendal. Kota Semarang yang dikelilingi oleh beberapa kabupaten, misalnya Kabupaten Kendal, Kabupaten Demak, dan Kabupaten Semarang. Untuk mempermudah transportasi umum masyarakat Kota Semarang dengan Kabupaten Kendal maka diadakan program BRT Trans Jateng. Program ini merupakan sebagai salah satu upaya dari pemerintah Provinsi Jawa Tengah dalam mengatasi kemacetan lalulintas di kawasan sekitar Kota Semarang, Kabupaten Semarang dan Kabupaten Kendal yang merupakan kawasan Industri oleh sebab itu dilakukan penambahan armada angkutan umum BRT Trans Jateng. Khusus di Daerah Kabupaten Kendal ada penambahan BRT program Trans Jateng yang diluncurkan oleh Gubernur Jawa Tengah dengan Bupati Kendal. Pengoperasian BRT Trans Jateng wilayah Mangkang-Weleri yang menghubungkan antar Kabupaten Kendal dan Kota Semarang hadir sebagai upaya pemerintah dalam mewujudkan pelayanan lalulintas bebas kemacetan dan mempermudah masyarakat dalam transportasi angkutan umum yang aman, tertib, lancar, dan terpadu. Namun dari kebijakan tersebut juga akan menimbulkan permasalahan baru yang akan dihadapi oleh pemerintah lokal (Kabupaten Kendal).

BRT Trans Jateng sudah dioperasikan antar wilayah Kabupaten Semarang-Kota Semarang. Selain wilayah tersebut, ada penambahan wilayah pengoperasian BRT Trans Jateng. Penambahan tersebut meliputi wilayah Kabupaten Kendal-Kota Semarang dengan rute wilayah Mangkang-Weleri. Adapun tujuan dari penambahan BRT tersebut mengurangi kemacetan lalulintas yang disebabkan oleh buruh pabrik atau pekerja di kawasan KIW, KIK dan Kawasan Candi yang kebanyakan dari Kabupaten Kendal. BRT Trans Jateng Kabupaten Kendal - Kota Semarang beroperasi pada bulan Oktober 2019 yang diresmikan oleh Gubernur Jateng bersama Bupati Kendal. Pada awal keberadaannya, animo masyarakat sangat tinggi untuk beralih ke transportasi ini karena di nilai nyaman dan relatif murah bagi masyarakat. Di sisi lain, keberadaan BRT Trans Jateng (Mangkang-Weleri) juga dapat memberi dampak negatif bagi moda transportasi umum daerah di Kabupaten Kendal, sehingga akan menimbulkan tumpang tindih antara angkutan umum daerah (angkutan umum daerah rute Sukorejo-Mangkang dan angkutan umum daerah rute Weleri-Mangkang) dengan BRT Trans Jateng (Mangkang-Weleri). Dari uraian latar belakang permasalahan di atas maka perlu dilakukan penelitian tentang "Dampak Tumpang Tindih Keberadaan BRT Trans Jateng (Mangkang-Weleri) Terhadap Angkutan Umum Daerah di Kabupaten Kendal". Hasil dari penelitian ini dapat dimanfaatkan untuk memahami permasalahan terhadap Dampak Tumpang Tindih Keberadaan BRT Trans Jateng (Mangkang-Weleri) terhadap Angkutan Umum Daerah di Kabupaten Kendal.

\section{Landasan Teori}

\section{1 Transportasi}

Transportasi dapat diartikan sebagai suatu proses pergerakan atau perpindahan orang/barang dari suatu tempat ke tempat lain dengan menggunakan suatu teknik atau cara tertentu untuk maksud dan tujuan tertentu dalam moda transportasi [1]. Sedangkan transportasi atau transportasi dapat diartikan sebagai tindakan atau kegiatan mengangkut atau memindahkan muatan (barang dan orang) dari suatu tempat ke tempat lain, atau dari tempat asal ke tempat tujuan yang ditentukan [2]. Sementara itu transportasi adalah suatu siklus perpindahan barang atau manusia dari satu tempat ke tempat lainnya dengan menggunakan moda transportasi berupa kendaraan [3]. Dengan demikian dapat dikatakan bahwa transportasi merupakan aktivitas pergerakan yang membawa sesuatu (penumpang/barang) untuk dipindahkan dari satu tempat ke tempat lain dengan menggunakan kendaraan yang memiliki tujuan tertentu dalam moda transportasi.

\section{2 Angkutan Umum}

Angkutan umum (public transport) adalah semua jenis moda transportasi sesuai kebutuhan mobilitas pergerakan barang/orang, demi kepentingan masyarakat banyak/umum dalam memenuhi kebutuhannya, baik transportasi darat, laut maupun transportasi udara [1]. Angkutan umum penumpang 
perkotaan adalah semua jenis angkutan umum yang melayani perjalanan (trips) penumpang dari tempat asal (origin) ketujuan (destination) dalam wilayah perkotaan. Moda angkutan umum merapakan sarana transportasi perkotaan yang tidak dapat dipisahkan dari sistem kegiatan perkotaan, khususnya bagi masyarakat pengguna angkutan umum yang tidak mempunyai pilihan moda lain untuk melaksanakan kegiatan atau aktifitas. Transportasi umum di perkotaan sangat dibutuhkan masyarakat perkotaan lebih tinggi di karena kebutuhan pengguna layanan transportasi lebih besar di bandingkan dengan masyarakat perdesaan. Jumlah kepemilikan kendaraan pribadi pada tahun ke tahun bertambah, berbanding lurus dengan kesejahteraan setiap masyarakat. Dengan alasan tersebut kepemilikan kendaraan yang setiap masa ke masa semakin bertambah menyebabkan penurunana jumlah pengguna angkutan umum, selain pada faktor tersebut salah satu penyebab terjadinya penurunan [4].

\section{3 Bus Rapid Transit (BRT)}

Bus Rapid Transit merupakan suatu tranportasi massal berbasis bus yang memberikan mobilitas perkotaan yang cepat, nyaman, dan hemat biaya pada suatu infrastruktur jalur terpisah, memiliki karakteristik operasional yang cepat dengan frekuensi tertentu serta sistem pemasaran dan layanan pelanggan yang prima [5]. Sistem Bus Rapid Transit (BRT) adalah angkutan umum yang berbasis pada jalan dimana memanfaatkan jalur-jalur khusus seperti bus way dan ekslusif untuk memudahkan perjalanan transportasi umum tanpa adanya hambatan samping lalulintas dalam moda transportasi. Sedangkan Bus Rapid Transit adalah sarana angkutan umum dengan moda bus BRT dimana kendaraan akan berjalan pada lintasan khusus berada di sisi jalur cepat atau jalur khusus untuk menghindari hambatan samping lalulintas. Selain itu sistem yang dipergunakan adalah sistem tertutup dimana penumpang dapat naik dan turun hanya pada halte-halte dan tentunya harus dilengkapi dengan sistem tiket baik berupa tiket untuk sekali jalan ataupun berlangganan dengan mekanisme prabayar. Agar para penumpang nyaman pada saat menuju dan meninggalkan halte maka disediakan fasilitas penyeberangan orang yang landai, petugas keamanan pada setiap halte, jadwal waktu perjalanan dan juga tidak adanya pedagang kaki lima baik di halte maupun jembatan penyebarangan kecuali pada tempat tampat yang telah ditentukan. Selain itu agar mudah menuju dan meninggalkan lajur bus way maka dari lokasi-lokasi tertentu akan disediakan trayek angkutan umum menuju lokasi tujuan. Jalur armada BRT merupakan jalur khusus untuk lintasan bus dengan maksud untuk meningkatkan efisiensi sistem transportasi umum, yaitu mempersingkat waktu perjalanan dan biaya transportasi dengan system mekanisme prabayar.

\section{Metodologi Penelitian}

Dalam penelitian ini yang digunakan adalah penelitian kuantitatif dengan menggunakan teknik observasi, penyebaran angket, wawancara dan dokumentasi dalam penelitian. Lokasi penelitian yang digunakan tersebut berada pada kawasan jalur yang dilalui oleh BRT Trans Jateng (Mangkang-Weleri). Adapun jalur tersebut meliputi Kecamatan Mangkang (Semarang) dan beberapa kecamatan di wilayah Kabupaten Kendal, seperti Kaliwungu, Kendal, Patebon, Cepiring, Gemuh, dan Weleri yang merupakan jalur utama yang dilalui oleh BRT Trans Jateng (Mangkang-Weleri). Jalur tersebut merupakan jalur pantura di Kabupaten Kendal Provinsi Jawa Tengah. Observasi penelitian ini adalah penumpang angkutan umum BRT Trans Jateng (Mangkang-Weleri) dan Bus rute Sukorejo-Mangkang dan Bus rute Weleri-Mangkang.

Adapun berdasarkan sumber penelitian adalah data yang digunakan dalam penelitian ini diklasifikasikan ke dalam dua golongan yakni sumber data primer dan data sekunder. Dalam penelitian ini, populasi yang diambil adalah dampak penumpang angkutan umum terhadap tumpang tindih keberadaan BRT Trans Jateng (Mangkang-Weleri). Adapun jumlah populasi penelitian ini sebanyak 30 penumpang BRT Trans Jateng rute Mangkang-Weleri. Tujuan penelitian ini merupakan pengambilan data penelitian dengan metode sampel yang di ambil adalah simple random sampling atau sampel acak sederhana, dimana setiap unit populasi memiliki kemungkinan (probabilitas) yang sama untuk diambil sebagai sampel. Penelitian menetapkan 15 orang sampel yang didapatkan dari penumpang BRT Trans Jateng (Mangkang-Weleri). Variabel penelitian ini adalah sebagai ciri individu, obyek, gejala yang dapat diukur secara kuantitatif. Variabel penelitian ini yang digunakan dalam proses identifikasi masalah, 
ditentukan berdasarkan kajian teori yang digunakan Adapun variabel penelitian dalam penelitian ini berupa :

$\mathrm{X}=$ Dampak Tumpang Tindih Keberadaan BRT Trans Jateng (Mangkang-Weleri)

$\mathrm{Y}=$ Dampak Tumpang Tindih antara BRT Trans Jateng dengan Angkutan Umum Daerah Kabupaten Kendal

Sehingga rumusan variable penelitian ini, yang diambil adalah Dampak Tumpang Tindih Keberadaan BRT Trans Jateng (Mangkang-Weleri) terhadap Angkutan Umum Daerah di Kabupaten Kendal. Pengambilan waktu penelitian ditentukan berdasarkan observasi awal yang dilakukan peneliti pada waktu tanggal 15 Februari 2020 sampai dengan tanggal 15 Maret 2020 (sebelum pandemi Covid19). Setelah pengambilan observasi awal peneliti melanjutkan penelitian untuk mengambil data penelitian kemudian penelitian berlanjut pada pada tanggal 13 Agustus 2020 sampai dengan pada tanggal 13 September 2020. Dari pengamatan atau observasi awal tersebut, penulis menyimpulkan bahwa pada hari Senin dan Rabu kapasitas penumpang BRT sangat padat dikarenakan mayoritas penumpang adalah karyawan dan anak sekolah. Sedangkan pada hari Sabtu dipilih karena pada hari tersebut terjadi penurunan kapasitas penumpang BRT yang disebabkan oleh liburnya sejumlah karyawan dan anak sekolah. Untuk penentuan jam didasarkan pada waktu dimana BRT mengalami peningkatan kapasitas penumpang. Adapun bagan alir penelitian pada gambar 1 tahapan praproses:

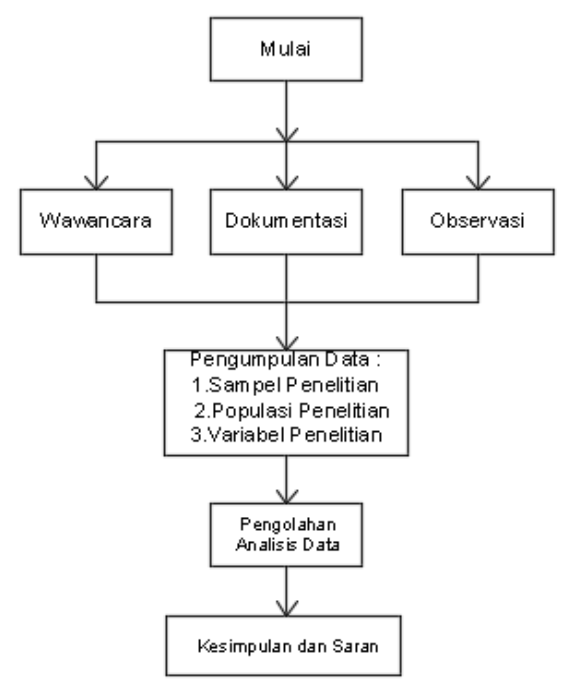

Gambar 1. Tahapan Penelitian

\section{Analisa Data}

\subsection{Sumber Data Penelitian}

Jenis penelitian ini yang digunakan sifatnya jenis data kuantitatif. Adapun berdasarkan sumber data dalam penelitian ini diklasifikasikan ke dalam dua golongan yakni sumber data primer dan data sekunder. Adapun penjabaran dari kedua sumber data tersebut yaitu sebagai berikut:

1. Sumber data primer

Sumber data primer merupakan data yang diambil langsung oleh peneliti dengan cara menggali sumber asli secara langsung melalui informasi yamg di dapatkan saat observasi dan wawancara. Sumber yang dimaksud berupa benda-benda, situs, kata dan tindakan dari sampel. Penelitian mengambil data secara langsung melalui observasi dan wawancara dengan para penumpang BRT Trans Jateng (Mangkang-Weleri) dan penumpang Bus rute Sukorejo-Mangkang dan Bus rute Weleri-Mangkang.

2. Sumber data sekunder 
Sumber data sekunder merupakan sumber data kedua diluar kata dan tindakan, namun data ini tidak diabaikan dan memiliki kedudukan penting sebagai penguat data yang diperoleh dari pengelola armada BRT Trans Jateng. Data sekunder berupa sumber tertulis, majalah, surat kabar, buletin, jurnal dan hasil penelitian yang relevan. Data sekunder juga dapat berupa foto-foto kegiatan statistik. Data-data yang peneliti peroleh berupa data tentang kebijakan pemerintah dengan adanya BRT Trans Jateng (Mangkang-Weleri) yang merupakan data sekunder sebagai data pendukung di dalam penelitian ini.

3. Metode Pengumpulan Data

Penelitian ini menggunakan jenis sumber data yang diperoleh secara lisan dan tertulis. Adapun teknik pengumpulan data yang digunakan dalam penelitian ini adalah metode observasi, wawancara, angket/ kuesioner dan dokumentasi saat pengambilan data penelitian.

\subsection{Hasil Analisis Menggunakan SPSS Uji Regresi}

Adapun hasil uji analisis data adalah sebagai berikut :

a. Uji Normalitas

Uji Normalitas adalah sebuah uji yang dilakukan dengan tujuan untuk menilai sebaran data pada sebuah kelompok data atau variabel, apakah sebaran data tersebut berdistribusi normal ataukah tidak. Uji Normalitas berguna untuk menentukan data yang telah dikumpulkan berdistribusi normal atau diambil dari populasi normal dari data penyebaran angket.

1) Uji Hipotesis

$\mathrm{H}_{0} \quad$ : Data berdistribusi normal

$\mathrm{H}_{1} \quad$ : Data tidak berdistribusi normal

2) Kriteria Pengujian

Jika Sig pada output tabel Tests of Normality $>0,05$ maka $\mathrm{H}_{0}$ diterima.

3) Intepretasi Hasil

Pada output Tests of Normality, di kolom Shapiro-Wilk diperoleh nilai sig. sebesar 0,727 dan 0,102 dimana keduanya mempunyai nilai lebih dari 0,05 maka terima $\mathrm{H} 0$ artinya data berdistribusi normal.

b. Uji Regresi

1) Hipotesis :

$\mathrm{H}_{0} \quad$ : Tidak ada dampak tumpang tindih keberadaan BRT Trans Jateng (Mangkang-Weleri) terhadap angkutan umum daerah di Kabupaten Kendal.

$\mathrm{H}_{1} \quad$ : Ada dampak tumpang tindih keberadaan BRT Trans Jateng (Mangkang-Weleri) terhadap angkutan umum daerah di Kabupaten Kendal.

2) Uji : Terima $\mathrm{H}_{1}$ jika nilai Sig <0,05 (alpha)

3) Simpulan : Berdasarkan hasil tersebut dapat disimpulkan bahwa ada dampak tumpang tindih keberadaan BRT Trans Jateng (Mangkang-Weleri) terhadap angkutan umum daerah di Kabupaten Kendal. Dikarenakan nilai Sig sebesar 0,002 dimana 0,002 kurang dari 0,05. Berdasarkan grafik keberadaan BRT dapat disimpulkan bahwa data linear dan mempunyai nilai $\mathrm{R}^{2}$ (R Square) sebesar 0,542. Yang berarti terdapat pengaruh keberadaan BRT Trans Jateng (Mangkang-Weleri) terhadap adanya tumpang tindih BRT Trans Jateng (Mangkang-Weleri) dan angkutan umum daerah di Kabupaten Kendal sebesar 54,2\%.

Berdasarkan grafik juga dapat diketahui nilai persamaan regresinya yaitu : $\mathrm{Y}=8,46+0,77 * \mathrm{X}$ Dimana :

Y : Tumpang Tindih BRT Trans Jateng (Mangkang-Weleri) dan Angkutan Umum Daerah Di Kabupaten Kendal

$X$ : Keberadaan BRT

Dari hasil grafik persamaan tersebut dapat disimpulkan bahwa terjadi tumpang tindih antara BRT Trans Jateng (Mangkang-Weleri) dan Angkutan Umum Daerah terutama pada bus rute WeleriMangkang dan bus rute Sukorejo-Mangkang. 


\subsection{Profil Lokasi Penelitian}

\subsubsection{Gambaran Umum Lokasi Penelitian}

Lokasi penelitian ini berada pada kawasan jalur yang dilalui oleh BRT Trans Jateng (MangkangWeleri) yang terdapat di jalan pantura Kendal. Adapun jalur tersebut meliputi Kecamatan Mangkang (Semarang) dan beberapa kecamatan di wilayah Kabupaten Kendal, seperti Kaliwungu, Kendal, Patebon, Cepiring, Gemuh, dan Weleri yang merupakan jalur utama yang dilalui oleh BRT Trans Jateng (Mangkang-Weleri). Jalur tersebut merupakan jalur pantura di Kabupaten Kendal Provinsi Jawa Tengah. Lokasi penelitian ini adalah masyarakat penumpang angkutan umum BRT Trans Jateng (Mangkang-Weleri) dan Bus rute Sukorejo-Mangkang dan Bus rute Weleri-Mangkang. Adapun untuk Peta Rute Perjalanan BRT Trans Jateng Makang-Weleri dapat dilihat seperti pada Gambar 2. Peta Rute Perjalanan BRT Trans Jateng Makang-Weleri.

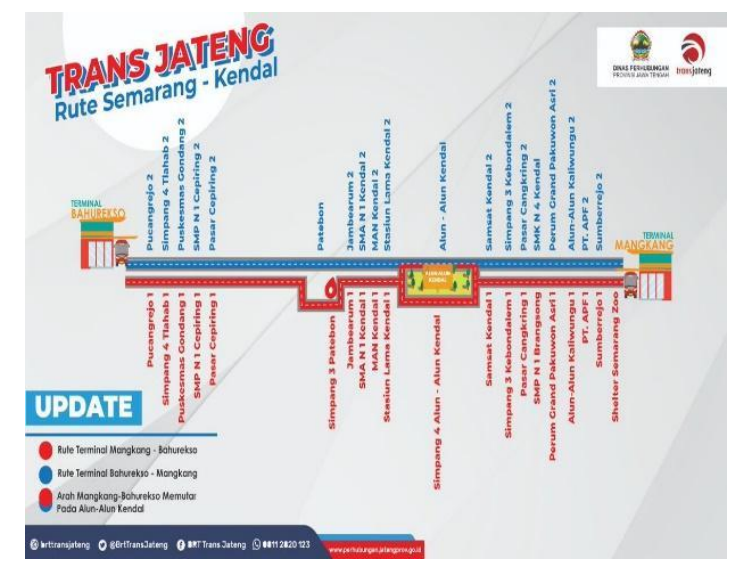

\section{Gambar 2. Peta Rute Perjalanan BRT Trans Jateng Makang-Weleri.}

\subsubsection{Gambaran Angkutan Umum Daerah di Kabupaten Kendal}

Sistem transportasi di Kabupaten Kendal pada dasarnya terdiri dari moda transportasi darat. Transportasi di Kabupaten Kendal yang masih didominasi moda darat termasuk angkutan umum seperti bus, angkot, taksi, dan lain-lain. Kabupaten Kendal berada di jalur pantura yang sangat ramai dan terdapat kawasan industry yang meliputi KIK, KIW dan kawasan Candi.

Angkutan umum daerah di Kabupaten Kendal terbagi menjadi 2 rute, yaitu:

1. Bus lokal rute Mangkang-Weleri

Bus ini berukuran sedang dengan satu pintu. Kapasitas penumpang sekitar 15-20 orang. Rute perjalanannya meliputi terminal Mangkang, Kaliwungu, Brangsong, Kendal, Patebon, Cepiring, Tlahab, Pucangrejo, dan berakhir di pasar Weleri. Tarif angkutan umum bus lokal ini berkisar Rp. 12.000,- sampai dengan Rp. 15.000,- dari terminal Mangkang sampai pasar Weleri. Bus lokal ini beroperasi setiap hari mulai pukul 05.30 WIB sampai dengan pukul 19.00 WIB setelah itu tidak ada transportasi umum. Dalam bus ini tidak ada fasilitas pendingin ruangan / AC, sehingga banyak penumpang bus merasa kurang nyaman. Adapun gambaran umum bus lokal Makang-Weleri dapat di lihat pada Gambar 3. Bus Rute Mangkang-Weleri.

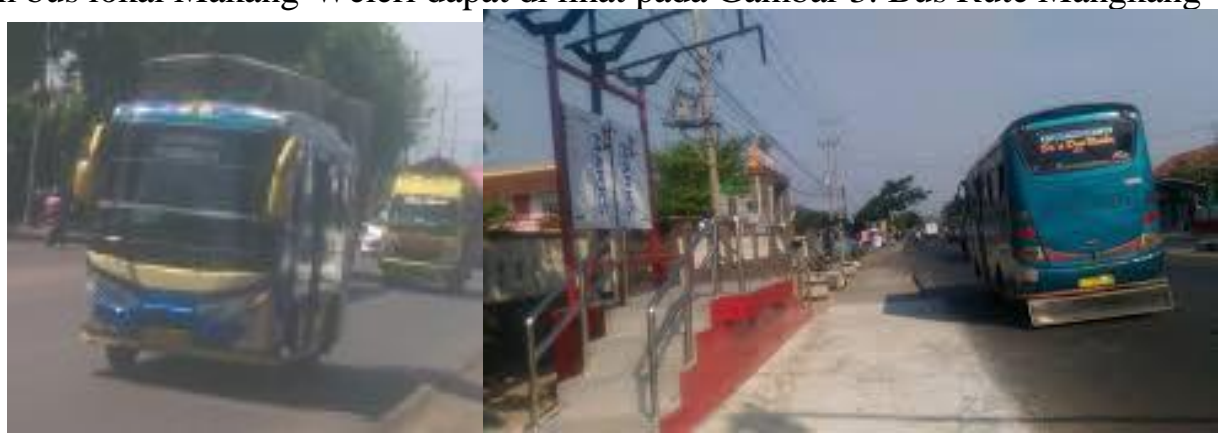




\section{Gambar 3. Bus Rute Mangkang-Weleri}

2. Bus rute Mangkang-Sukorejo

Adapun deskripsi gambaran umum bus ini berukuran agak besar dengan dua pintu. Kapasitas penumpang sekitar 30-35 orang. Rute perjalanannya meliputi terminal Mangkang, Kaliwungu, Brangsong, Kendal, Patebon, Cepiring, Tlahab, Pucangrejo, weleri dan berakhir di terminal Sukorejo. Tarif angkutan umum bus rute Magkang-Sukorejo ini berkisar Rp. 25.000,- sampai Rp 30.000,- dari terminal Mangkang sampai terminal Sukorejo. Bus Rute Makang-Sukorejo ini beroperasi setiap hari mulai pukul 05.30 WIB sampai dengan pukul 19.00 WIB. Dalam bus ini tidak ada fasilitas pendingin ruangan / AC sehingga para penumpang bus kurang nyaman. Adapun kondisi bus Rute Mangkang-Sukorejo dapat dilihat pada Gambar 4.

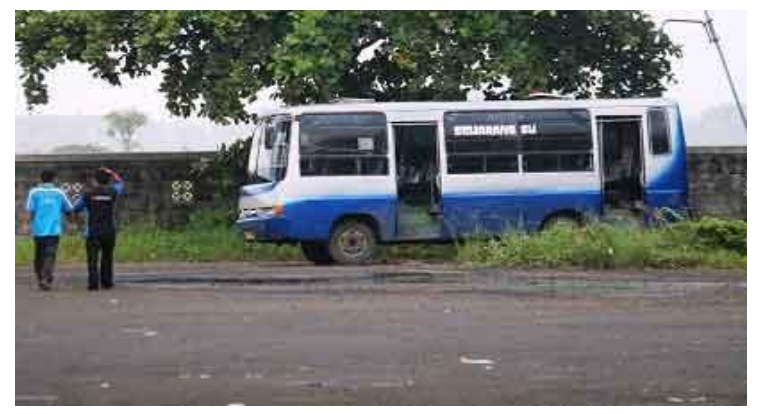

Gambar 4. Bus Rute Mangkang-Sukorejo

\subsubsection{Gambaran Umum BRT Trans Jateng (Mangkang-Weleri)}

BRT Trans Jateng (Mangkang-Weleri) adalah layanan angkutan umum berupa armada bus berlantai tunggal yang beroperasi di jalan raya strategis pantura Semarang-Kendal. Tujuan Utama dioperasikannya BRT Trans Jateng (Mangkang-Weleri) adalah untuk mengurangi kemacetan lalulintas di kawasan strategis pantura Semarang-Kendal. Selain itu BRT Trans Jateng (Mangkang-Weleri) juga bertujuan untuk mengakomodasi kebutuhan penumpang transportasi umum serta masyarakat di Kawasan Strategis pantura Semarang-Kendal dengan menghadirkan angkutan umum yang aman, murah dan nyaman serta cepat. BRT Trans Jateng (Mangkang-Weleri) adalah moda transportasi umum yang menghubungkan titik-titik tertentu kawasan terminal Mangkang, Kaliwungu, Brangsong, Ketapang, Kendal, Patebon, Cepiring, Tlahab, Pucangrejo, dan berakhir di terminal Bahurekso. BRT ini mulai pertama kali beroperasi pada bulan Oktober 2019 yang diresmikan oleh Bapak Ganjar Pranowo selaku Gubernur Jawa Tengah bersama Ibu Mirna Annisa selaku Bupati Kendal. Adapun kelebihan dan kekurangan dari BRT Trans Jateng (Mangkang-Weleri) adalah sebagai berikut:
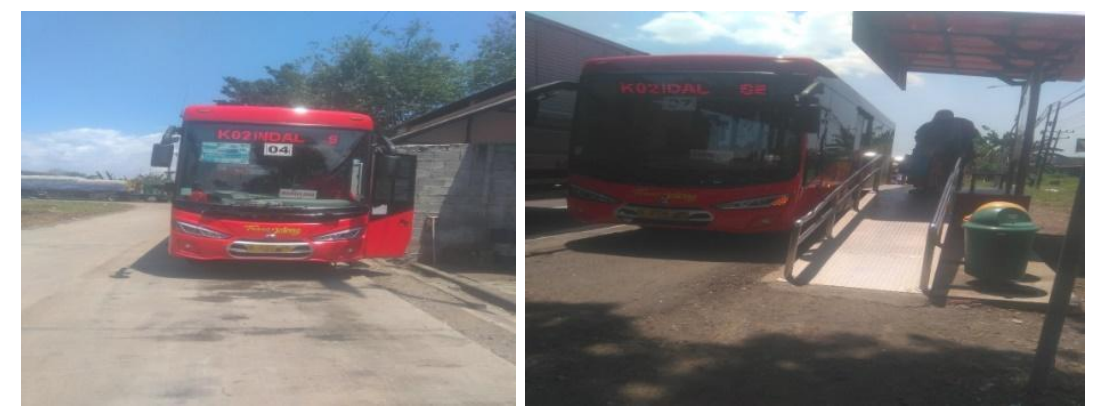

Gambar 5. Armada Bus BRT Trans Jateng (Mangkang-Weleri) 
Adapun gambaran operasional BRT Trans Jateng (Mangkang-Weleri) yang dapat dilihat pada Gambar 5. Armada Bus BRT Trans Jateng (Mangkang-Weleri) untuk deskripsi gambaran armada bus adalah sebagai berikut:

1. Rute

Rute BRT Trans Jateng (Mangkang-Weleri) memiliki rute perjalanan mulai dari terminal Mangkang, Kaliwungu, Brangsong, Ketapang, Kendal, Patebon, Cepiring, Tlahab, Pucangrejo, dan berakhir di terminal Bahurekso.

2. Fasilitas Armada

Fasilitas armada BRT Trans Jateng (Mangkang-Weleri) adapun untuk fasilitas dilengkapi dengan tempat duduk prioritas untuk para penumpang lanjut usia, ibu hamil dan penumpang dengan anak serta penumpang berkebutuhan khusus. Adapun untuk fasilitas lain untuk kenyamanan penumpang transportasi umum BRT Trans Jateng (Mangkang-Weleri) adalah Pendingin Udara / AC (Air Conditioning), musik, papan informasi pemberhentian selanjutnya untuk para penumpang. Selain itu juga dilengkapi dengan alat pegangan tangan bagi para penumpang yang berdiri dan terdapat pewangi ruangan di dalam bus.

3. Halte

Halte Bus BRT Trans Jateng, armada bus BRT Trans Jateng (Mangkang-Weleri) telah beroperasi pada satu rute perjalanan. Dari rute tersebut terdapat 39 halte pemberhentian bus BRT yang terdiri dari 20 halte rute terminal Mangkang ke terminal Bahurekso dan 19 halte rute terminal Bahurekso ke terminal Mangkang. Adapun titik halte BRT Trans Jateng dapat di uraikan adalah sebagai berikut :

a. $\quad$ Rute Mangkang-Bahurekso : Shelter Semarang Zoo, Sumberejo 1, PT. APF 1, Alun-Alun Kaliwungu 1, Perum Grand Pakuwon Asri 1, SMP N 1 Brangsong, Pasar Cangkring 1, Simpang 3 Kebondalem 1, Samsat Kendal 1, Simpang 4 Alun-Alun Kendal, Stasiun Lama Kendal 1, MAN Kendal 1, SMA N 1 Kendal 1, Jambearum 1, Simpang 3 Patebon, Pasar Cepiring 1, SMP N 1 Cepiring 1, Puskesmas Gondang 1, Simpang 4 tlahab 1, dan Pucangrejo 1.

b. Rute Bahurekso-Mangkang: Terminal Mangkang, Sumberejo 2, PT. APF 2, Alun-Alun Kaliwungu 2, Perum Grand Pakuwon Asri 2, SMK N 4 Kendal, Pasar Cangkring 2, Simpang 3 Kebondalem 2, Samsat Kendal 2, Alun-Alun Kendal, Stasiun Lama Kendal 2, MAN Kendal 2, SMA N 1 Kendal 2, Jambearum 2, Patebon, Pasar Cepiring 2, SMP N 1 Cepiring 2, Puskesmas Gondang 2, Simpang 4 tlahab 2 dan Pucangrejo 2

4. Tarif

BRT Trans Jateng (Mangkang-Weleri) telah beroperasi pada bulan Oktober 2019 dengan satu rute perjalanan dari Mangkang sampai Weleri. BRT ini beroperasi setiap hari waktu operasi BRT Trans Jateng dimulai dari pukul 05.30 WIB sampai dengan 18.00 WIB dan selesai operasional pada pukul 19.00 WIB di terminal Mangkang dan terminal Bahurekso. Sedangkan interval antar bus BRT sekitar 10 sampai dengan 15 menit. Karcis dapat dibeli di halte BRT Trans Jateng (Mangkang-Weleri) dengan tarif tiket pemberangkatan sebesar Rp 4.000 untuk umum untuk satu kali perjalanan jauh atau dekat.

\section{Kapasitas}

Pemerintah Provinsi Jawa Tengah telah menyiapkan sebanyak 14 bus ukuran sedang BRT ( Bus Rapid Transit ) Trans Jateng (Mangkang-Weleri). Bus ini memiliki kapasitas 30-35 penumpang. Dengan rincian ada sekitar 19 orang yang duduk dan ada sekitar 16 orang yang berdiri. Sehingga daya tampung penumpang keseluruhan BRT Trans Jateng (Mangkang-Weleri) adalah sekitar 490 orang per hari sebelum adanya era pandemi covid-19. Sedangkan selama era pandemi covid-19 ini kapasitas penumpang berkurang sekitar 50\% sehingga daya serapnya menjadi 245 orang per hari. 


\subsection{Kesenjangan Fasilitas antara BRT Trans Jateng (Mangkang-Weleri) dan Angkutan Umum Daerah di Kabupaten Kendal}

Berdasarkan pengamatan yang peneliti lakukan, terdapat kesenjangan fasilitas antara BRT Trans Jateng (Mangkang-Weleri) dan Angkutan Umum Daerah di Kabupaten Kendal. Hal ini dapat mengakibatkan beralihnya minat masyarakat di Kabupaten Kendal untuk menggunakan moda transportasi baru yang di nilai lebih nyaman dibandingkan dengan Angkutan Umum Daerah di Kabupaten Kendal. Moda transportasi baru tersebut berupa BRT Trans Jateng (Mangkang-Weleri). Adapun kelebihan dan kelemahan kesenjangan fasilitas BRT Trans Jateng (Mangkang-Weleri) dengan Angkutan Umum Daerah di Kabupaten

\subsection{Solusi dari Dampak Tumpang Tindih Keberadaan BRT Trans Jateng (Mangkang-Weleri) terhadap Angkutan Umum Daerah di Kabupaten Kendal}

Berdasarkan dari permasalahan diatas maka peneliti dapat menyimpulkan beberapa solusi / alternatif dari masalah yang diteliti. Solusi tersebut sekiranya dapat membantu ke-dua belah pihak yang bersangkutan yaitu antara pihak Pengelola Angkutan Umum Daerah di Kabupaten Kendal dan Pengelola BRT Trans Jateng (Mangkang-Weleri). Adapun solusinya adalah sebagai berikut :

1. Sebaiknya ada kemitraan antara Pemerintah Provinsi Jawa Tengah, Pemerintah Kabupaten Kendal, dan Pemilik Angkutan Umum Daerah di Kabupaten Kendal terkait penertiban jadwal keberangkatan armada bus BRT Trans Jateng (Mangkang-Weleri) dengan Angkutan Umum Daerah.

2. Sebaiknya ada penertiban jam tunggu penumpang untuk Angkutan Umum Daerah yang terlalu lama supaya tidak terjadi tumpang tindih antara BRT Trans Jateng (Mangkang-Weleri) dengan Angkutan Umum Daerah.

3. Terkait penjadwalan keberangkatan bus BRT Trans Jateng (Mangkang-Weleri) bisa dikondisikan dengan angkutan umum daerah agar tidak terjadi tumpang tindih penumpang.

4. Adanya perbaikan fasilitas armada Angkutan Umum Daerah di Kabupaten Kendal sehingga para penumpang bisa lebih nyaman.

5. Pemprov Jateng dan Pemkab Kendal mengajak kerjasama dengan para pemilik bus Angkutan Umum Daerah untuk dilibatkan dalam penambahan armada bus BRT Trans Jateng (MangkangWeleri) yang baru.

6. Perekrutan pengemudi BRT Trans Jateng (Mangkang-Weleri) yang baru dapat diambilkan dari pengemudi Angkutan Umum Daerah yang sangat lama untuk waktu pemberangkatan.

\section{Kesimpulan}

Berdasarkan hasil penelitian tentang dampak tumpang tindih keberadaan BRT Trans Jateng (Mangkang-Weleri) terhadap angkutan umum daerah di Kabupaten Kendal, maka dapat disimpulkan bahwa :

1. Dampak tumpang tindih dalam BRT Trans Jateng (Mangkang-Weleri) terhadap Angkutan Umum Daerah di Kabupaten Kendal yang memiliki 20 rute sebagai berikut :

a. Rute Mangkang-Bahurekso : Shelter Semarang Zoo, Sumberejo 1, PT. APF 1, Alun-Alun Kaliwungu 1, Perum Grand Pakuwon Asri 1, SMP N 1 Brangsong, Pasar Cangkring 1, Simpang 3 Kebondalem 1, Samsat Kendal 1, Simpang 4 Alun-Alun Kendal, Stasiun Lama Kendal 1, MAN Kendal 1, SMA N 1 Kendal 1, Jambearum 1, Simpang 3 Patebon, Pasar Cepiring 1, SMP N 1 Cepiring 1, Puskesmas Gondang 1, Simpang 4 tlahab 1, dan Pucangrejo 1.

b. Rute Bahurekso-Mangkang: Terminal Mangkang, Sumberejo 2, PT. APF 2, Alun-Alun Kaliwungu 2, Perum Grand Pakuwon Asri 2, SMK N 4 Kendal, Pasar Cangkring 2, Simpang 3 Kebondalem 2, Samsat Kendal 2, Alun-Alun Kendal, Stasiun Lama Kendal 2, MAN Kendal 2, SMA N 1 Kendal 2, Jambearum 2, Patebon, Pasar Cepiring 2, SMP N 1 Cepiring 2, Puskesmas Gondang 2, Simpang 4 tlahab 2 dan Pucangrejo 2. 
2. Tumpang tindih keberadaan BRT Trans Jateng (Mangkang-Weleri) dengan bus angkutan umum daerah dari hasil penyebaran angket / kuesioner uji regresi $\mathrm{Y}=8,46+0,77 * \mathrm{X}$. Dari hasil uji regresi pengaruh keberadaan BRT Trans Jateng (Mangkang-Weleri) terhadap adanya tumpang tindih sebesar nilai R2 (R Square) sebesar 0,542. Yang berarti terdapat pengaruh keberadaan BRT Trans Jateng (Mangkang-Weleri) terhadap adanya tumpang tindih BRT Trans Jateng (MangkangWeleri) dan angkutan umum daerah di Kabupaten Kendal sebesar 54,2\%.

3. Pemerintah Jawa Tengah telah mempersiapkan 14 bus ukuran sedang BRT Trans Jateng (Mangkang-Weleri) yang memiliki kapasitas penumpang 30-35 orang penumpang dengan rincian ada sekitar 19 orang duduk dan 16 orang berdiri sehingga daya serap BRT Trans Jateng (Mangkang-Weleri) keseluruhan adalah 490 orang per hari. Selama masa pandemi covid-19 ini terjadi penurunan kapasitas penumpang sekitar 50\% sehingga daya serapnya menjadi 245 orang per hari.

\section{Referensi}

[1] Budhiartha, Nyoman. (2011). Peranan Transportasi dalam Pariwisata. Studi Kasus: Pemilihan Wisata (Dtw/ Destinasi) oleh Wisatawan di Bali. Jurnal Ilmiah Teknik Sipil, 15(2), 195-204.

[2] Adisasmita, Adji Sakti. 2011. Transportasi dan Pengembangan Wilayah. Yogyakarta: Graha Ilmu.

[3] Wardhani, Apriliyani D. 2012. Evolusi Aktual Aktivitas Urban Tourism di Kota Bandung dan Dampaknya terhadap Pembentukkan Tempat - Tempat Rekreasi. Jurnal Pengembangan Wilayah dan Kota. Semarang: Biro Penerbit Planalogi Undip

[4] Firdausi, Mutiara, Hafizah, Nafilah El, 2020. "Analisis Kemampuan dan Kemauan Membayar (ATP - WTP) Penumpang Bus Kota Rute Purabaya - Bratang”. Jurnal Teknologi dan Manajemen, Vol. 1, No. 1 Januari 2020: 62-66.

[5] Wright, L., \& Fjellstrom, K. (2002). Sustainable Urban Transport Sourcebook for Policy-Makers in Developing Cities. 